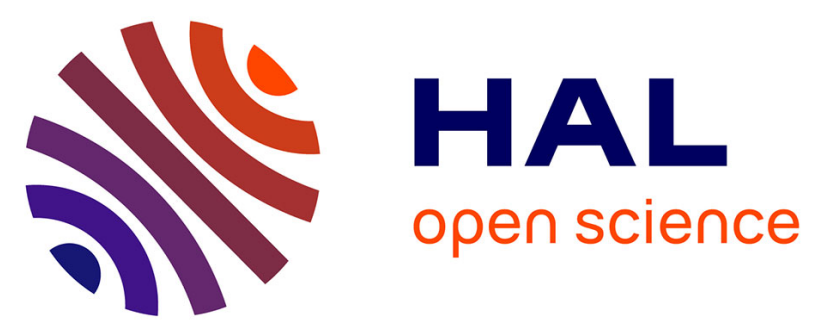

\title{
Effects of Combined Vigorous Interval Training Program and Diet on Body Composition, Physical Fitness, and Physical Self-Perceptions Among Obese Adolescent Boys and Girls
}

Olivier Rey, Jean-Marc Vallier, Caroline Nicol, Charles-Symphorien Mercier, Christophe Maïano

\section{To cite this version:}

Olivier Rey, Jean-Marc Vallier, Caroline Nicol, Charles-Symphorien Mercier, Christophe Maïano. Effects of Combined Vigorous Interval Training Program and Diet on Body Composition, Physical Fitness, and Physical Self-Perceptions Among Obese Adolescent Boys and Girls. Pediatric Exercise Science, 2017, 29 (1), pp.73-83. 10.1123/pes.2016-0105 . hal-01649504

\section{HAL Id: hal-01649504 https://hal-amu.archives-ouvertes.fr/hal-01649504}

Submitted on 29 Nov 2017

HAL is a multi-disciplinary open access archive for the deposit and dissemination of scientific research documents, whether they are published or not. The documents may come from teaching and research institutions in France or abroad, or from public or private research centers.
L'archive ouverte pluridisciplinaire HAL, est destinée au dépôt et à la diffusion de documents scientifiques de niveau recherche, publiés ou non, émanant des établissements d'enseignement et de recherche français ou étrangers, des laboratoires publics ou privés. 


\title{
Effects of Combined Vigorous Interval Training Program and Diet on Body Composition, Physical Fitness, and Physical Self-Perceptions Among Obese Adolescent Boys and Girls
}

\author{
Olivier Rey and Jean-Marc Vallier \\ University of Toulon \\ Caroline Nicol \\ Aix Marseille University \\ Charles-Symphorien Mercier \\ Le Noble Age Group \\ Christophe Maïano \\ University of Quebec in Outaouais
}

\begin{abstract}
Purpose: This study examined the effects of a five-week intervention combining vigorous interval training (VIT) with diet among twenty-four obese adolescents. Fourteen girls and ten boys (aged 14-15) schooled in a pediatric rehabilitation center participated. Methods: The VIT intensity was targeted and remained above $80 \%$ of maximal heart rate (HR) and over six kilocalories per minute. Pre- and postintervention measures were body composition (BMI, weight, body fat percentage), physical self-perceptions (PSP), physical fitness (6-min walking distance and work) and its associated physiological responses $\left(\mathrm{HR}_{\text {peak }}\right.$ and blood lactate concentration). A series of two-way analyses of variance or covariance controlling for weight loss were used to examine the changes. Results: Significant improvements were found in body composition, physical fitness and PSP (endurance, activity level, sport competence, global physical self-concept and appearance). In addition, boys presented higher levels of perceived strength and global physical self-concept than girls. Finally, there was a significant increase in perceived endurance, sport competence, and global physical self-concept in girls only. Conclusion: This five-week VIT program combined with diet represents an effective means for improving body composition, physical fitness, and PSP in obese adolescents, the effects on PSP being larger among girls.
\end{abstract}

Keywords. pediatric obesity; interval training; vigorous exercise; physical self-perceptions, physical fitness

Substantial evidence indicates that physical activity is positively associated with weight loss and long-term weight control (5). The relationship between obesity and physical activity (PA) consists in a vicious circle:

Rey and Vallier are with the Universite de Toulon, LAMHESS, France. Nicol is with the Aix Marseille University, CNRS, ISM, Inst. Movement Sci, Marseille, France. Mercier is with the AJO®Les Oiseaux, Pediatric Obesity Follow-up and Rehabilitation Care, Le Noble Age Group, Sanary-sur-Mer, France. Maïano is with the Cyberpsychology Laboratory, Dept. of Psychoeducation and Psychology, Université du Québec en Outaouais (UQO), Canada. Address author correspondence to Olivier Rey at olivier.rey@univ-amu.fr. insufficient PA leads to overweight/obesity, which can lead to decreased PA (4). In addition, evidence of several well-being constructs that include subjective well-being and health, mood, and self-esteem suggests that PA is an important contributor to mental well-being (19). Similarly, physical self-perception (PSP) could be considered as a central psychological construct of obese adolescents for adherence to PA (18). Although it is still unclear whether and how poor PSP might influence overweight/ obese youth's motivation to participate in PA, such information is considered relevant to the development of effective PA programs (43). As overweight/obese adolescents present lower involvement in PA and a less positive attitude toward PA than their normal-weight peers, it has been suggested that PA programs should include more 
fun and attractive exercises to reverse this situation (13). For instance, since there are more barriers to PA for girls than for boys (51), programs specifically designed for girls, could be helpful. These suggestions agree with the general idea that youth with positive attitudes and high self-efficacy would be more attracted to PA and have more intention to participate in PA (22).

Most PA interventions among young people with obesity have focused on either aerobic training (38) or resistance training (41). For example, Klijn and colleagues (26) examined the effects on obese adolescents of a 12-week aerobic training program and found a significant increase in physical fitness through improved walking functional capacity and aerobic indices. Tan and colleagues (44) examined the effects on obese children of an eight-week program that included various forms of vigorous PAs targeted at a mean heart rate (HR) of $165 \pm 15 \mathrm{bpm}$ and mean energy expenditure of within $3.52-7.98 \mathrm{kcal} / \mathrm{min}$. Positive improvements were found in body composition, cardiovascular fitness index, and physical fitness (i.e., walking and jumping performances). Their study also showed the potential use of HR and energy expenditure measurements to control exercise intensity during various short forms of PA. Morano and colleagues (37) examined the psychophysical effects of an eight-month multimodal aerobic program on obese adolescent boys and girls. They found significantly reduced body mass index (BMI), increased physical fitness and improved perceived physical abilities, for both sexes.

In the last decade, more research has focused on the effects of PA on physical fitness and PSP, but varied training programs and diverging findings have been reported. Among these studies, Daley and colleagues (9) reported significant improvements of physical self-worth and global self-esteem in obese adolescents, regardless of their sex, despite unchanged BMI and physical fitness after an eight-week PA program (30 min, three times per week, of moderate intensity aerobic exercises) followed by a six-week home aerobic program. Yu and colleagues (50) reported among overweight/obese children significant changes, regardless of their sex, in body composition and increased actual physical capacities, perceived physical strength, and perceived endurance after a sixweek program combining diet with resistance exercise. Goldfield and colleagues (21) examined the effects of a 22-week program of aerobic and/or resistance training on obese adolescents' PSP. Regardless of the training type, significant improvements were found for most of the PSP subdomains (i.e., sport competence, physical condition, body satisfaction, physical strength, and physical self-worth) and global self-esteem. In this study, like in most previous ones, sex-based differences were not assessed. Thus, although the literature shows that overweight/obese girls have significantly lower PSP $(3,42)$ and physical fitness (12) than their male counterparts, it is still unknown how girls' and boys' PSP and physical fitness differ according to their PA experience.

Recent emphasis has been put on high-intensity interval training (HIIT), which is considered a promising and time-efficient strategy to promote health in sedentary overweight/obese individuals (e.g., 1,2). Commonly, HIIT is of short duration and performed above the lactate threshold, with intermittent rest periods that provide sufficient time to recover and to perform additional highintensity bouts. HIIT is recognized for its lower volume but higher impact on body composition and fat loss than commonly used aerobic exercises of moderate intensity (e.g., 6,10,29). Moreover, HIIT has been demonstrated to enhance perceived enjoyment (25). Nevertheless, inconsistencies remain concerning the actual HIIT design in terms of working levels, volume and duration, and rest periods (for a review, see 11). A promising alternative could rely on vigorous interval training (VIT) that consists of an intermittent type of PA that share similar characteristics to HIIT, but that it is performed at submaximal rates and potentially using various forms of exercise. As recently emphasized by Ekkekakis and colleagues (15), the challenge in limiting avoidance and nonadherence in designing PA programs for obese individuals lies in maximizing energy expenditure while striking the "right" balance between intensity and duration. The efficacy of such program types has not yet been examined in obese adolescent boys and girls.

The present study aimed to assess the combined effects of a five-week VIT program and diet on body composition (body weight, BMI, and body fat percentage), physical fitness (six-minute walking distance and work) and physiological responses (heart rate and blood lactate concentration) as well as PSP among obese adolescent boys and girls. Significant improvements which varied by sex were expected in obese adolescents' physical fitness and PSP. More specifically, given that girls have lower PSP and physical fitness than boys, it was hypothesized that the effects of the five-week VIT program and diet on PSP and physical fitness would be greater for girls than for boys.

\section{Methods}

\section{Participants and Procedures}

A total of 30 obese adolescents, aged 14-15 (without medical disorders, e.g., metabolic, cardiac or orthopedic), were recruited in a pediatric rehabilitation center in Southern France. Six participants were excluded from the analysis because they failed to complete the program due to several absences or medical reasons. This study thus focuses on the 24 remaining participants (14 girls and 10 boys) who performed all the training sessions and completed all the measures. These participants (see Table 1 for detailed anthropometric and body composition data) were categorized as obese based on their body fat percentage $(36.75 \pm 7.04 \%)$ and BMI $(32.64 \pm 4.88 \mathrm{~kg} /$ $\mathrm{m}^{2}$ ). Boys and girls were both classified as obese (sexand-age 95th percentile) using the Centers for Disease Control and Prevention (CDC) growth reference (27).

The protocol was constructed in accordance with the Declaration of Helsinki and met France's ethical require- 


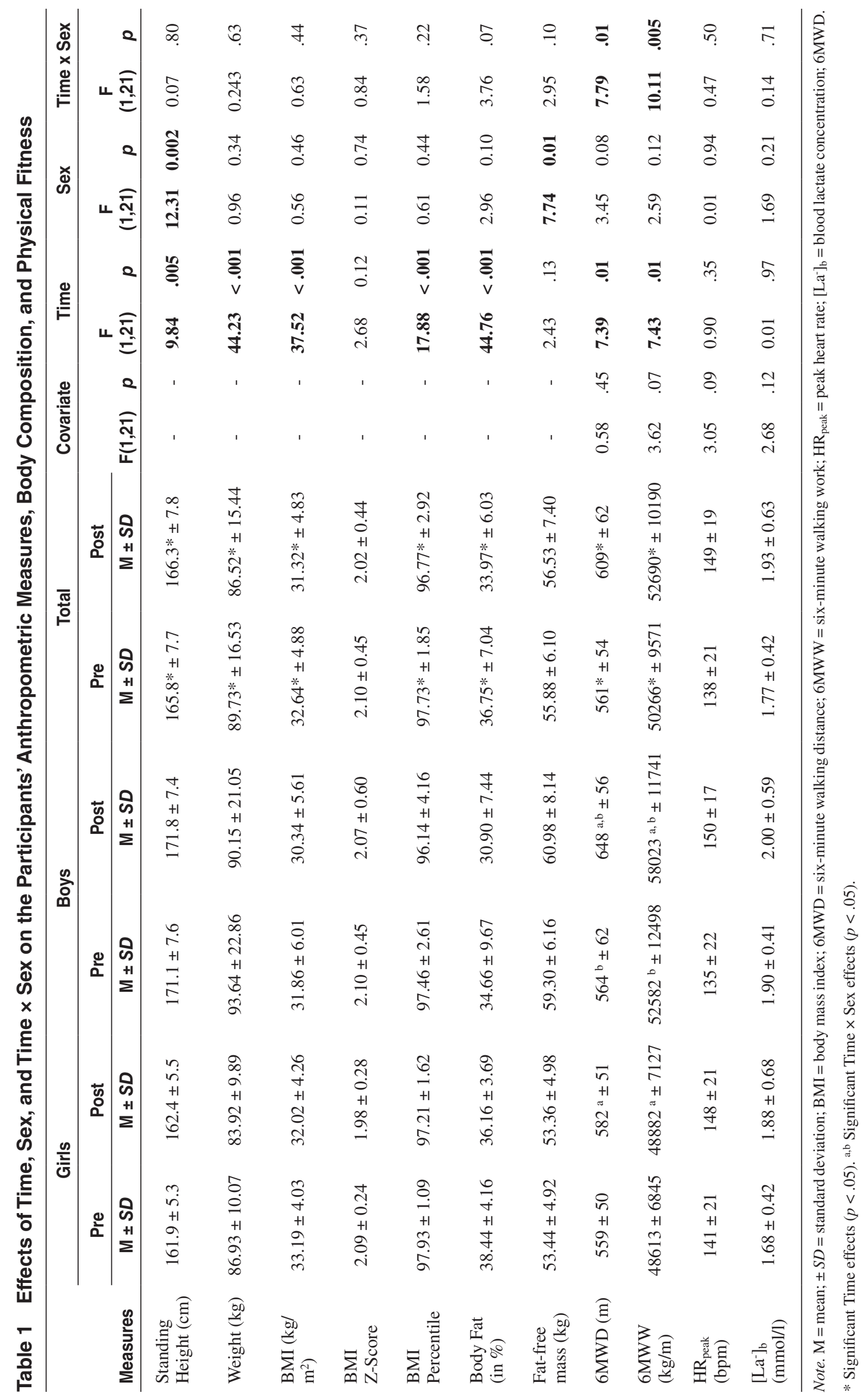


ments for human research. Permission to conduct the study was first obtained from the administration and medical staff of the pediatric rehabilitation center. The adolescents' parents or legal representatives received an information letter regarding the study, and only the adolescents who returned the cosigned consent forms participated.

\section{Vigorous Interval Training Program Combined With a Diet}

The VIT program took place during a dietary care followup. After a nutritional and lifestyle assessment, all the participants followed the same dietary program for rebalancing their nutrition at the beginning of the intervention. The program evolved into a more autonomous management of food groups and portions with educational support based on the principle of energetic balance. The food portions were not weighed, but corresponded to visual cues. Food was consumed four times per day. The average energy intake was $2000 \mathrm{kcal} /$ day (17\% protein, $33 \%$ fat and $50 \%$ carbohydrates) for girls and $2200 \mathrm{kcal} /$ day $(17 \%$ protein, $30 \%$ fat and $53 \%$ carbohydrates) for boys.

The obese participants were involved in three sessions per week, over five weeks, of 45 min of various types of interval training in basketball, bike 'n' run, and noncontact fist and kick boxing with a similar 10-min warm-up followed by different periods of work and rest. These three types of training were each performed: (a) in three series of 10 min' work / three minutes' passive rest in a three-on-three basketball game; (b) in two series of three minutes' work / three minutes' passive rest of random "all-out" bike (against a mechanical resistance of 4/10 on a cycle ergometer-Kettler "Golf M" model, Germany) and run performed at a free cadence for a maximal distance; and (c) in three series of eight-minute sequences of repeating $10 \mathrm{~s}$ "all-out" knocks against a bag / $20 \mathrm{~s}$ of passive rest separated by four minutes of intermediate passive rest. Each of these exercises/sports was proposed to the participants for five weeks. Every interval training session was considered vigorous based on the two following criteria (23): (a) an energy expenditure of over $6 \mathrm{kcal} /$ min (about four Metabolic Equivalent of Task [METs] for our population); and (b) a relative required effort of at least $80 \%$ of the theoretical maximal heart rate $\left(\mathrm{HR}_{\max }\right)$ based on the definition of the American College of Sports Medicine (14). The overall mean values for the training intensity for the 15 sessions were $9.37 \pm 1.81 \mathrm{kcal} / \mathrm{min}$ or $6.2 \pm 0.4$ METs, and $89.30 \%$ of the theoretical $H_{\text {max }}$ (i.e., $177 \pm 9 \mathrm{bpm}$ ). These values assess the actual PA intensity level. All of the VIT sessions were conducted by the first author of this research under the supervision of the medical staff of the pediatric rehabilitation center. The days, times, and geographic and material conditions were identical for each training session.

\section{Measures}

Body Composition. All anthropometric measures were taken before and after the VIT program by the medical staff. They used a Harpenden stadiometer for the participants' standing height (with a precision of $1 \mathrm{~cm}$ ) and a Tanita impedance measurement device (BC 418, Japan) for their bodyweight and body fat percentage. BMI was calculated as follows: body weight / height $\mathrm{x}$ height (in $\mathrm{kg} / \mathrm{m}^{2}$ ). The BMI scores were then converted into BMI percentiles and $\mathrm{z}$-scores according to the CDC growth reference for youth (27).

Physical Fitness. To assess the submaximal functional capacities of the participants, the six-minute walk test (6MWT) was proposed to them before and after the VIT program. This protocol has been validated for obese children (17). To comply with the American Thoracic Society (46) standard, the test was performed in a 40-m corridor with a hard surface. Standardized encouragement was provided every minute. Patients were allowed to stop at any time during the test, but they were told to walk as far as they felt able to for six minutes without running. Walking performance was quantified by using the six-minute walking distance (6MWD) and the six-minute walking work $(6 \mathrm{MWW}=6 \mathrm{MWD} \mathrm{x}$ body weight), the latter parameter being reported as adequate for the evaluation of the participants' fitness levels (7). To limit the influence of a learning effect (i.e., better pacing strategy) between the pre- and postintervention tests, a familiarization test session was performed the previous week. The pre- and the post-6MWT were performed individually under the same conditions (i.e., no spectator except the investigation staff, same time of day, and same timed normative encouragement sentences for both tests).

Blood lactate concentration $\left[\mathrm{La}^{-}\right]_{\mathrm{b}}$. The $\left[\mathrm{La}^{-}\right]_{\mathrm{b}}$ was assessed using a portable lactate analyzer (Lactate Pro, Arkray, Japan). To do so, the medical staff took a blood sample from the participants' earlobe at the end of the 6MWT.

Heart Rate Measurement and Target Values. HR was recorded throughout the 6MWT (Polar RS 400, Polar Electro Oy, Kempele, Finland). Peak heart rate value $\left(\mathrm{HR}_{\text {peak }}\right)$ was estimated based on the mean of the four highest values between the fourth and fifth minute to avoid a false value due to a faster pace at the end of the test. HR was continuously recorded during all VIT sessions to obtain the HR peak $\left(\mathrm{HR}_{\text {peak }}\right)$ and mean (HR $\left.\mathrm{H}_{\text {mean }}\right)$.

The HR target value of VIT was established based on the percentage of the estimation of the maximum HR $\left(\mathrm{HR}_{\max }\right)$ using [208- $(0.7 \times$ age $\left.)\right]$, a formula provided by Tanaka and colleagues (45). To be considered vigorous work, each VIT session aimed at inducing $\mathrm{HR}_{\text {peak }}$ of at least $80 \%$ of the participants' theoretical $\mathrm{HR}_{\max }(157 \mathrm{bpm}$ on average for adolescents aged 14.6 years).

Assessment of Energy Intensity and Expenditure. A validated (40) triaxial accelerometer (RT3, Stayhealthy Inc., Monrovia, CA) was used to assess the intensity and energy expenditure of the participants' PA (48) from the start to the end of each training session. The accelerometer was carried on the belt on the right hip. To 
assess each training session, the energy expenditure was expressed in $\mathrm{kcal} / \mathrm{min}$ and estimated in METs.

Physical Self-Perceptions. PSP were measured with the French version of the short form of the Physical Self-Description Questionnaire (PSDQ-S; 31, 33). This 40-item questionnaire measures 11 physical selfdimensions: coordination (CO), strength (ST), flexibility (FL), endurance (EN), global self-esteem (GSE), health (HE), activity (AC), body fat (BF), sport competence (SC), global physical self-concept (GPSC), and appearance (AP). Participants rate each sentence using a six-point Likert scale ranging from 1 (false) to 6 (true). The PSDQ-S was completed before and after the intervention. The internal consistency means of the various scales measured before $\left(\alpha_{\text {pre }}\right)$ and after $\left(\alpha_{\text {post }}\right)$ the intervention were mostly acceptable $\left[\mathrm{CO}\left(\alpha_{\text {pre }}=0.82 ; \alpha_{\text {post }}=0.79\right), \operatorname{ST}\left(\alpha_{\text {pre }}=0.81\right.\right.$; $\left.\alpha_{\text {post }}=0.67\right), \mathrm{FL}\left(\alpha_{\text {pre }}=0.84 ; \alpha_{\text {post }}=0.83\right), \mathrm{EN}\left(\alpha_{\text {pre }}=0.82\right.$; $\left.\alpha_{\text {post }}=0.83\right), \operatorname{GSE}\left(\alpha_{\text {pre }}=0.69 ; \alpha_{\text {post }}=0.50\right), \mathrm{HE}\left(\alpha_{\text {pre }}=\right.$ $\left.0.82 ; \alpha_{\text {post }}=0.60\right), \operatorname{AC}\left(\alpha_{\text {pre }}=0.84 ; \alpha_{\text {post }}=0.78\right), \operatorname{SC}\left(\alpha_{\text {pre }}\right.$ $\left.=0.85 ; \alpha_{\text {post }}=0.79\right), \operatorname{GPSC}\left(\alpha_{\text {pre }}=0.85 ; \alpha_{\text {post }}=0.80\right)$, and $\left.\operatorname{AP}\left(\alpha_{\text {pre }}=0.85 ; \alpha_{\text {post }}=0.88\right)\right]$. However, the BF subscale was excluded from the analyses due to its unsatisfactory internal consistency $\left(\alpha_{\text {pre }}=0.54 ; \alpha_{\text {post }}=0.31\right)$.

\section{Statistical Analyses}

All analyses were performed using Statistica 12.0 (Statsoft Inc., Tulsa, OK, USA). A two-way repeated measures analysis of variance (ANOVA) was used to examine the effects of time (pre- vs. postintervention), sex, and their interaction (Time $\times$ Sex) on standing height, bodyweight, BMI, BMI z-scores, BMI percentiles and BF percentage. Finally, a two-way repeated measure analysis of covariance (ANCOVA) controlling for delta-weight changes between pre- and postintervention was used to examine the effects of time, sex and their interaction on the $6 \mathrm{MWD}, 6 \mathrm{MWW}, \mathrm{HR}_{\text {peak }},\left[\mathrm{La}^{-}\right]_{\mathrm{b}}$, and PSP. In cases of significance $(p<.05)$, a Student Newman-Keuls post hoc test was used. The effect sizes were estimated using Cohen's $d(8)$.

\section{Results}

\section{Anthropometric Measures and Body Composition}

Findings from the two-way repeated-measures ANOVA showed significant effects of Time for standing height, weight, BMI, BMI percentile, and BF percentage. However, no significant differences were found for the BMI $\mathrm{Z}$-score or the fat-free mass (Table 1). More specifically, the significant differences revealed that participants: (a) increased their standing height by $0.36 \%(+0.6 \pm 0.7$ $\mathrm{cm}, d=0.08)$; (b) lost $3.6 \%$ of their initial weight $(-3.03$ $\pm 3.02 \mathrm{~kg}, d=-0.20)$; (c) reduced their BMI $(-1.32 \pm$ $\left.1.05 \mathrm{~kg} / \mathrm{m}^{2}, d=-0.27\right)$ and their BMI percentile $(-0.97 \pm$ $1.18, d=-0.40)$; and (d) reduced their BF percentage by $7.52 \%(-2.78 \pm 2.23 \%, d=-0.42)$. The significant effect of Sex on the standing height and fat-free mass variables (Table 1) indicated that, regardless of the testing time, the boys were taller $(+5.66 \%, d=1.40)$ and presented more fat-free mass than the girls $(+10.9 \%, d=1.05)$. None of the anthropometric or body composition parameters was significantly influenced by the effect of Time $\times$ Sex.

\section{Physical Fitness and Physiological Responses to the 6MWT}

As illustrated in the lower part of Table 1, the covariate (Weight changes) and the participants' sex did not significantly influence any of the walking performances or any of the physiological measures. Significant effects of Time and Time $x$ Sex were observed for the 6MWD (Figure 1A) and the 6MWW (Figure 1B). The time effect
A

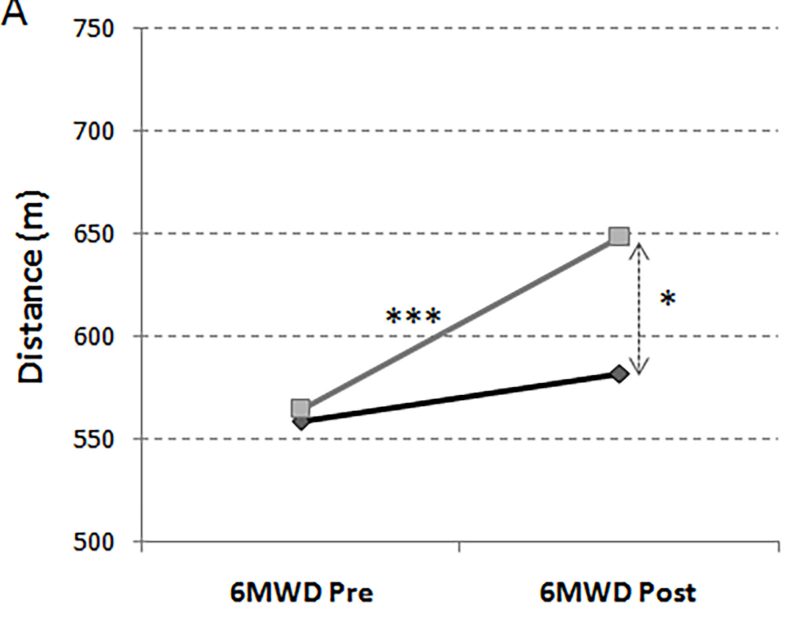

B

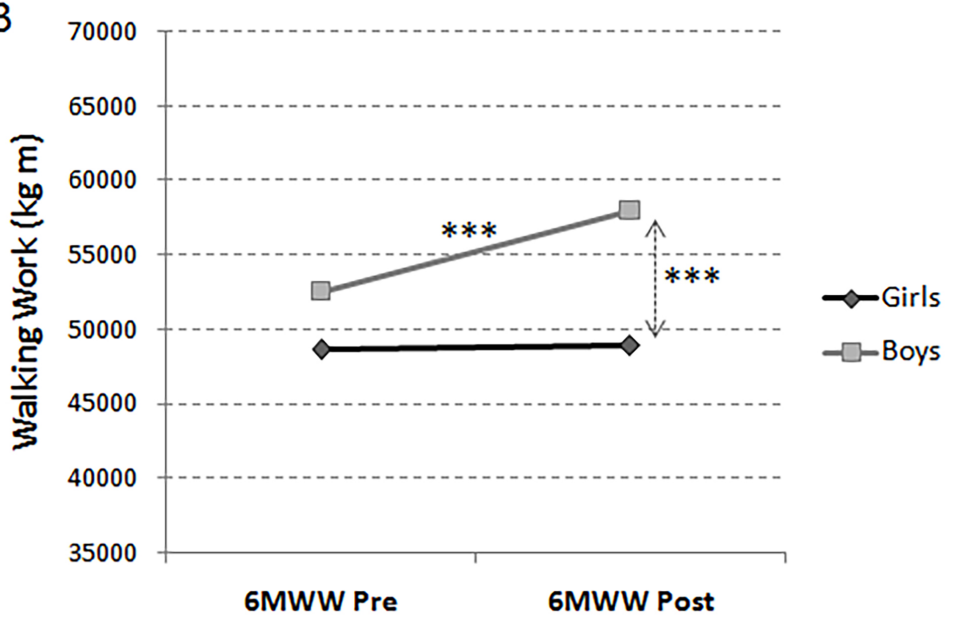

Figure 1 - Boys' and girls' group mean values at pre- and postinterventions for the six-minute walking distance (6MWD) (A) and the six-minute walking work (6MWW) (B). Significant Post-Hoc Time and Sex effects: * $(p<.05)$, *** $(p<.001)$. 
showed an increase of 6MWD and 6MWW between preand postintervention. In addition, the Time $\mathrm{x}$ Sex effect showed significant increases in the 6MWD and 6MWW $(+48 \pm 58 \mathrm{~m}, d=0.83$ and $+2424 \pm 4711 \mathrm{~kg} / \mathrm{m}, d=0.25$, respectively) for the boys $(+84 \pm 61 \mathrm{~m}, p<.001, d=1.42$, and $+5441 \pm 4873 \mathrm{~kg} / \mathrm{m}, p<.001, d=0.45$, respectively), but not for the girls. At postintervention, the boys walked for a significantly longer distance $(+66.25 \mathrm{~m}$ in mean, $p$ $=.030, d=1.24)$ and produced more work $(+9140 \mathrm{~kg} / \mathrm{m}$ in mean, $p<.001, \mathrm{~d}=0.94$ ) than the girls. Finally, no effect of Time, Sex or Time $\times$ Sex was found for the physiological measures of $\left[\mathrm{La}^{-}\right]_{\mathrm{b}}$, and $\mathrm{HR}_{\text {peak }}$.

\section{Physical Self-Perceptions}

As illustrated in Table 2, none of the PSDQ-S subscales was significantly affected by the covariate (Weight changes). Subsequent analyses of the Time effects revealed significant pre-post intervention improvements of the $\mathrm{EN}(d=0.50), \mathrm{AC}(d=0.28), \mathrm{SC}(d=0.62)$, GPSC $(d=0.58)$, and AP $(d=0.31)$ subscales of the PSDQ-S. However, no significant effect was observed for the CO, ST, FL, GSE, and HE subscales. Referring to the significant Sex effect, boys presented significantly higher scores than girls in the ST $(d=0.94)$ and GPSC $(d=1.31)$ subscales of the PSDQ-S. In addition, a significant Time $x$ Sex effect was found for the EN (Figure 2A), SC (Figure 2B), and GPSC (Figure 2C) subscales of the PSDQ-S. Girls reported significantly higher levels of $\mathrm{EN}(p<.001$, $d=1.07), \mathrm{SC}(p=.002, d=1.02)$, and $\operatorname{GPSC}(p<.001$, $d=1.41$ ) between pre- and postintervention. In addition, girls had significantly lower levels of GPSC than boys at both pre- $(p=.007, d=-1.64)$ and postintervention $(p$ $<.001, d=-2.13)$.

\section{Discussion}

As attested by the mean values of HR and energy expenditure registered per training session, which were systematically above the targeted values, of $80 \% \mathrm{HR}_{\max }$ and $6 \mathrm{kcal} / \mathrm{min}$ (or $4 \mathrm{METs}$ ), the intensity of the training program was vigorous throughout its five weeks. These outcome values are consistent with those reported by Tan and colleagues (44) and Jakicic and colleagues (24), who examined closer types of exercise intensities with overweight or obese youths. This responds to the objective of eliciting an acute high level of energy expenditure while improving long-term physical fitness and body composition (e.g., 20).

\section{Changes in Body Composition and Physical Fitness}

The significant effects on body composition (body weight, BMI and BF) observed in both boys and girls are consistent with and greater than those reported in the literature for similar time periods of aerobic, resistance or combined exercises (e.g., 9,50,21). The 6MWD values before and after the exercise intervention are consistent with the performances reported for this population in the literature (17). The significant gain of $8.6 \%$ in the 6MWD values after five weeks is close to the gain reported by Tan and colleagues (44) after eight weeks of multicomponent activities at the lactate threshold intensity but without diet, and demonstrates the functional benefits of the present intervention. The associated gain in fitness is suggested by the increased $6 \mathrm{MWW}$ values independently of the weight loss, with better results for the boys as compared with the girls. In the absence of a Time x Sex effect on any of the anthropometric and body composition parameters, the gain in physical fitness observed in the boys could not be attributed to either growth or maturation. This suggests that the VIT program is more suitable for improving functional capacities in obese boys than obese girls. The nonsignificant change in the measured physiological parameters $\left([\mathrm{La}-]_{\mathrm{b}}, \mathrm{HR}_{\text {peak }}\right)$, despite the increase in 6MWD and 6MWW performance, shows that the metabolic cost is similar even with higher walking speeds, which suggests an improved walking economy. These results are of great importance as regards obese adolescents' higher metabolic cost in walking, compared with their normal-weight peers (39). As both the increase in physical fitness and the weight loss may improve metabolic outcome and explain a better efficiency (16), it is of further interest that the present weight changes did not significantly influence any of the walking performance or physiological measures. It is of further interest that these findings reinforce the physical fitness improvements provided by the VIT program.

\section{Physical Self-Perceptions}

No effect of the weight loss was observed in the results for PSP. This suggests that the significant effects observed on PSP may not have been influenced by weight changes but rather by the VIT program despite its short term. This is in contrast with longer-term studies on dietary and exercise programs among obese adults showing that weight loss was associated with changes in global self-esteem and PSP (e.g., 35). Such discrepancies are common in the literature. For example, a 5\% weight-loss threshold has been defined for a small improvement of health-related quality of life (49) and is considered the minimum reduction needed for mental health improvements in the review by Lasikiewicz and colleagues (28). However, Messier and colleagues (36) reported an increase in body esteem with a body-weight loss of only $3 \%$.

The findings showed a significant increase in several physical self-dimensions, including postintervention perceived endurance, activity level, sport competence, global physical self-concept and appearance after intervention. These results differ from those of the study by $\mathrm{Yu}$ and colleagues (50), who reported a time effect only on the scale of perceived strength, and a significant improvement of perceived endurance during a diet and resistance training program compared with diet alone. In addition, in contrast to the findings of Daley and colleagues (9) and Goldfield and colleagues (21), no significant effect 


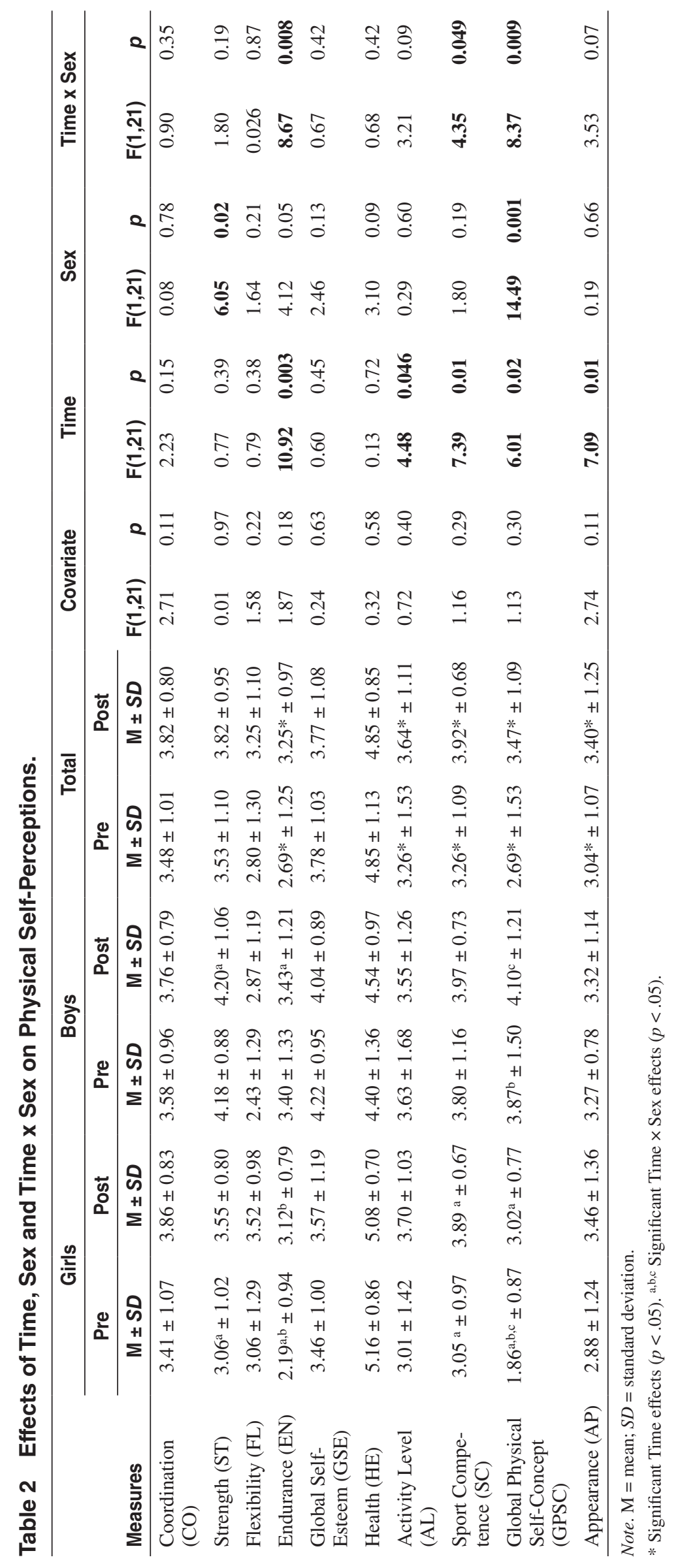




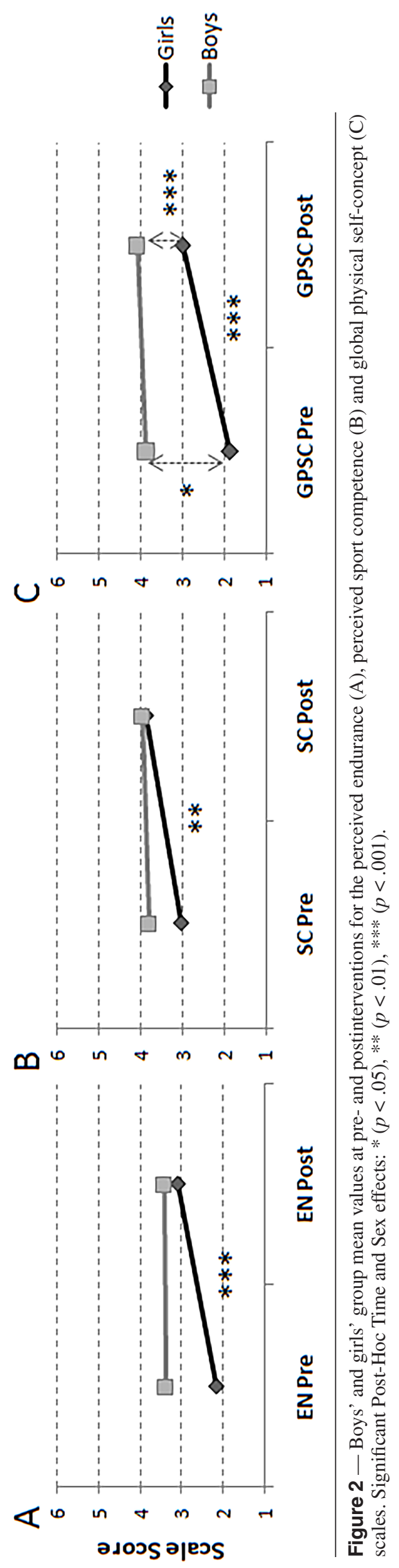


was observed for global self-worth in the current study. It can be hypothesized that the shortness of intervention in the current study could explain this absence of influence on global self-esteem, since most studies used longer-term programs. Indeed, Leith (30) reported a 12 -week threshold to induce a significant improvement in global self-esteem compared with programs of less than eight weeks.

However, the present findings show that obese adolescents' physical self-perceptions were reactive to a short-term program of five weeks of mixed VIT. Considering the lack of studies on the effects of VIT on PSP, it may be of interest to consider the findings reported for the most similar HIIT conditions. The present VIT results are consistent with the HIIT literature that reports a good tolerability, pleasant affective responses and self-efficacy beliefs after high-intensity intermittent exercise (25). Thus, considering that actual and perceived physical fitness were improved by the VIT program, it can be hypothesized that increased in walking functional capacities provided more well-being and satisfaction in participants. Defined as a multidimensional construct that includes endurance, muscular strength, flexibility, and motor coordination (47), an increase in physical fitness could also be related to so-far unsubstantiated changes in self-concept as reported by Berger (4).

A significant Sex effect showed that boys had higher baseline scores of perceived strength and global physical self-concept than girls. These results are consistent with those found in the literature among overweight and obese adolescents in the absence of any training program $(32,34)$. Furthermore, a significant effect of Time and Sex was found, revealing that, with time, girls significantly increased their scores for the endurance, sport competence, and global physical self-concept subscales with a strong effect size. These results are original considering that female adolescents consistently report less favorable perceptions of their physical self-worth than adolescent males $(32,34)$. Consequently, these findings revealed that the beneficial effects of this VIT program on PSP were greater in girls than in boys, despite their lower gains in the walking functional capacities.

\section{Limitations and Future Directions}

The findings of the current study must be interpreted with caution due to certain limitations. Firstly, the small sample size may have influenced the power of the statistical analyses. Secondly, this promising study did not compare its findings with those of participants who followed either other types of exercise programs or a diet only. Consequently, any objective proof of a better effect of VIT compared with aerobic or resistance training would merit further examination. Thirdly, participants were recruited in a specific context (i.e., rehabilitation pediatric center for obese youth) where their social interactions may have influenced their physical self-perceptions. Indeed, they may have compared themselves positively or negatively with similar peers or with others who did not participate in the program. Finally, because of the short duration of the program we do not know if the observed effects could be maintained over a longer period or whether the participants would adhere to or drop out of the program. Consequently, it would be interesting to examine the effects of this VIT program over a longer period compared with other exercise modalities (like continuous moderate or resistance training), and to include a control group as well as a follow-up of the cohort's attitudes toward physical activities after the end of the program.

\section{Conclusion}

The present study confirms the positive effect of a shortterm VIT program combined with a diet on body composition, walking performance, and PSP. The findings revealed that the effects of this program on PSP were greater among girls than boys. This program seems to be particularly adapted to obese adolescents for promoting PA. It would be a relevant alternative to aerobic or resistance programs, which require either a high volume of exercise or elevated loads involving risks for the joints and muscles of sedentary young people.

\section{Acknowledgments}

We thank the pediatric rehabilitation center, the staff and the youth of $\mathrm{AJO}^{\circledR}$ Les Oiseaux, Pediatric Obesity Follow-up, and Rehabilitation Care of "Le Noble Age" group for their support and participation in this study. The authors have no competing interests. The authors have no financial or other conflict of interest to disclose. They declare that the experiments comply with the current laws of France, the country in which the experiments were performed.

\section{References}

1. Alahmadi MA. High-intensity Interval Training and Obesity. J Nov Physiother. 2014. doi:10.4172/21657025.1000211

2. Andersen RE, Jakicic JM. Interpreting the physical activity guidelines for health and weight management. $J$ Phys Act Health. 2009; 6(5):651-656. PubMed doi:10.1123/ jpah.6.5.651

3. Babic MJ, Morgan PJ, Plotnikoff RC, Lonsdale C, White RL, Lubans DR. Physical activity and physical self-concept in youth: systematic review and meta-analysis. Sports Med. 2014; 44(11):1589-1601. PubMed doi:10.1007/ s40279-014-0229-z

4. Berger BG. Subjective well-being in obese individuals: the multiple roles of exercise. Quest. 2004; 56(1):50-76. doi:10.1080/00336297.2004.10491815

5. Blair SN, Jacobs, Jr. DR, Powell KE. Relationships between exercise or physical activity and other health behaviors. Public Health Rep. 1985; 100(2):172-180. PubMed

6. Boutcher SH. High-intensity intermittent exercise and fat loss. J Obes. 2011. PubMed doi:10.1155/2011/868305 
7. Chuang ML, Lin IF, Wasserman K. The body weightwalking distance product as related to lung function, anaerobic threshold and peakVO $V_{2}$ in COPD patients. Respir Med. 2001; 95(7):618-626. PubMed doi:10.1053/ rmed.2001.1115

8. Cohen J. Statistical power analysis for the behavioral sciences, 2nd ed. Hillsdale, New Jersey: Lawrence Erlbaum Associates; 1988.

9. Daley AJ, Copeland RJ, Wright NP, Roalfe A, Wales JK. Exercise therapy as a treatment for psychopathologic conditions in obese and morbidly obese adolescents: a randomized, controlled trial. Pediatrics. 2006; 118(5):21262134. PubMed doi:10.1542/peds.2006-1285

10. De Araujo ACC, Roschel H, Picanço AR, et al. Similar health benefits of endurance and high-intensity interval training in obese children. PLoS One. 2012; 7(8):e42747. PubMed doi:10.1371/journal.pone.0042747

11. De Feo P. Is high-intensity exercise better than moderateintensity exercise for weight loss? Nutr Metab Cardiovasc Dis. 2013; 23(11):1037-1042. PubMed doi:10.1016/j. numecd.2013.06.002

12. Deforche B, Lefevre J, Bourdeaudhuij I, Hills AP, Duquet W, Bouckaert J. Physical fitness and physical activity in obese and nonobese Flemish youth. Obes Res. 2003; 11(3):434-441. PubMed doi:10.1038/oby.2003.59

13. Deforche BI, De Bourdeaudhuij IM, Tanghe AP. Attitude toward physical activity in normal-weight, overweight and obese adolescents. J Adolesc Health. 2006; 38(5):560-568. PubMed doi:10.1016/j.jadohealth.2005.01.015

14. Donnelly JE, Blair SN, Jakicic JM, Manore MM, Rankin JW, Smith BK. American College of Sports Medicine Position Stand. Appropriate physical activity intervention strategies for weight loss and prevention of weight regain for adults. Med Sci Sports Exerc. 2009; 41(2):459-471. PubMed doi:10.1249/MSS.0b013e3181949333

15. Ekkekakis P, Vazou S, Bixby WR, Georgiadis E. The mysterious case of the public health guideline that is (almost) entirely ignored: call for a research agenda on the causes of the extreme avoidance of physical activity in obesity. Obes Rev. 2016. PubMed doi:10.1111/obr.12369

16. Ekman MJ, Klintenberg M, Björck U, Norström F, Ridderstråle M. Six-minute walk test before and after a weight reduction program in obese subjects. Obesity (Silver Spring). 2013; 21(3):e236-e243. PubMed doi:10.1002/ oby. 20046

17. Elloumi M, Makni E, Ounis OB, et al. Six-minute walking test and the assessment of cardiorespiratory responses during weight-loss programmes in obese children. Physiother Res Int. 2011; 16(1):32-42. PubMed doi:10.1002/ pri.470

18. Fox KR. Physical activity and mental health promotion: the natural partnership. J Public Ment Health. 2000; 2(1):4-12. doi:10.1108/17465729200000002

19. Fox KR. The effects of exercise on self-perceptions and self-esteem. Physical activity and psychological wellbeing. 2000,13:81-118.

20. Gibala MJ, Little JP, MacDonald MJ, Hawley JA. Physiological adaptations to low-volume, high-intensity interval training in health and disease. J Physiol.
2012; 590(5):1077-1084. PubMed doi:10.1113/ jphysiol.2011.224725

21. Goldfield GS, Kenny GP, Alberga AS, et al. Effects of aerobic training, resistance training, or both on psychological health in adolescents with obesity: The HEARTY randomized controlled trial. J Consult Clin Psychol. 2015; 83(6):1123-1135. PubMed doi:10.1037/ccp0000038

22. Hagger MS, Chatzisarantis NL, Harris J. From psychological need satisfaction to intentional behavior: Testing a motivational sequence in two behavioral contexts. Pers Soc Psychol Bull. 2006; 32(2):131-148. PubMed doi:10.1177/0146167205279905

23. Howley ET. Type of activity: resistance, aerobic and leisure versus occupational physical activity. Med Sci Sports Exerc. 2001; 33(6S):S364-S369. PubMed doi:10.1097/00005768-200106001-00005

24. Jakicic JM, Marcus BH, Gallagher KI, Napolitano M, Lang W. Effect of exercise duration and intensity on weight loss in overweight, sedentary women: a randomized trial. JAMA. 2003; 290(10):1323-1330. PubMed doi:10.1001/jama.290.10.1323

25. Jung ME, Bourne JE, Little JP. Where does HIT fit? An examination of the affective response to high-intensity intervals in comparison to continuous moderate- and continuous vigorous-intensity exercise in the exercise intensity-affect continuum. PLoS One. 2014; 9(12):e114541. PubMed doi:10.1371/journal.pone.0114541

26. Klijn PH, van der Baan-Slootweg OH, van Stel HF. Aerobic exercise in adolescents with obesity: preliminary evaluation of a modular training program and the modified shuttle test. BMC Pediatr. 2007; 7(1):7-19. PubMed doi:10.1186/1471-2431-7-19

27. Kuczmarski RJ, Ogden CL, Guo SS, et al. 2000 CDC Growth Charts for the United States: methods and development. Vital and health statistics. Series 11, Data from the national health survey. 2002;11(246):1-190.

28. Lasikiewicz N, Myrissa K, Hoyland A, Lawton CL. Psychological benefits of weight loss following behavioural and/or dietary weight loss interventions. A systematic research review. Appetite. 2014; 72:123-137. PubMed doi:10.1016/j.appet.2013.09.017

29. Lau PW, Wong DP, Ngo JK, Liang Y, Kim CG, Kim HS. Effects of high-intensity intermittent running exercise in overweight children. Eur J Sport Sci. 2015; 15(2):182190. PubMed doi:10.1080/17461391.2014.933880

30. Leith LM. Foundations of exercise and mental health. Fitness Information Technology; 2010.

31. Maïano C, Morin AJS, Mascret N. Psychometric properties of the short form of the Physical Self-Description Questionnaire in a French adolescent sample. Body Image. 2015; 12:89-97. PubMed doi:10.1016/j. bodyim.2014.10.005

32. Maïano C, Ninot G, Bilard J. Age and gender effects on global self-esteem and physical self-perception in adolescents. Eur Phys Educ Rev. 2004; 10(1):53-69. doi:10.1177/1356336X04040621

33. Marsh HW, Martin AJ, Jackson S. Introducing a short version of the physical self description questionnaire: new strategies, short-form evaluative criteria, and appli- 
cations of factor analyses. J Sport Exer Psychol. 2010; 32(4):438-482. PubMed doi:10.1123/jsep.32.4.438

34. Marsh HW. Age and gender effects in physical selfconcepts for adolescent elite athletes and nonathletes: A multicohort-multioccasion design. J Sport Exer Psychol. 1998; 20:237-259.

35. Megakli T, Vlachopoulos SP, Thøgersen-Ntoumani C, Theodorakis Y. Impact of aerobic and resistance exercise combination on physical self-perceptions and self-esteem in women with obesity with one-year follow-up. Int $J$ Sport Exerc Psychol. 2015; XXX:1-22. doi:10.1080/161 2197X.2015.1094115

36. Messier V, Karelis AD, Prud'homme D, Primeau V, Brochu M, Rabasa-Lhoret R. Identifying metabolically healthy but obese individuals in sedentary postmenopausal women. Obesity (Silver Spring). 2010; 18(5):911-917. PubMed doi:10.1038/oby.2009.364

37. Morano M, Colella D, Rutigliano I, Fiore P, PettoelloMantovani M, Campanozzi A. A multi-modal training programme to improve physical activity, physical fitness and perceived physical ability in obese children. $J$ Sports Sci. 2014; 32(4):345-353. PubMed doi:10.1080/026404 14.2013.824602

38. Paes ST, Marins JCB, Andreazzi AE. Metabolic effects of exercise on childhood obesity: a current view. Rev Paul Pediatr. 2015; 33(1):122-129. PubMed doi:10.1016/j. rpped.2014.11.002

39. Peyrot N, Thivel D, Isacco L, Morin JB, Duché P, Belli A. Do mechanical gait parameters explain the higher metabolic cost of walking in obese adolescents? J Appl Physiol. 2009; 106(6):1763-1770. PubMed doi:10.1152/ japplphysiol.91240.2008

40. Powell SM, Rowlands AV. Intermonitor variability of the RT3 accelerometer during typical physical activities. Med Sci Sports Exerc. 2004; 36(2):324-330. PubMed doi:10.1249/01.MSS.0000113743.68789.36

41. Schranz N, Tomkinson G, Olds T. What is the effect of resistance training on the strength, body composition and psychosocial status of overweight and obese children and adolescents? A systematic review and meta-analysis.
Sports Med. 2013; 43(9):893-907. PubMed doi:10.1007/ s40279-013-0062-9

42. Sonstroem RJ. Physical self-concept: assessment and external validity. Exerc Sport Sci Rev. 1997; 26:133-164. PubMed

43. Sung RYT, Yu CW, So RCH, Lam PKW, Hau KT. Selfperception of physical competences in preadolescent overweight Chinese children. Eur J Clin Nutr. 2005; 59(1):101-106. PubMed doi:10.1038/sj.ejen.1602044

44. Tan S, Yang C, Wang J. Physical Training of 9-10 Year Old Children With Obesity to Lactate Threshold Intensity. Pediatr Exerc Sci. 2010; 22(3):477-485. PubMed doi:10.1123/pes.22.3.477

45. Tanaka H, Monahan KD, Seals DR. Age-predicted maximal heart rate revisited. J Am Coll Cardiol. 2001; 37(1):153156. PubMed doi:10.1016/S0735-1097(00)01054-8

46. Travis WD, King TE, Bateman ED, et al. American Thoracic Society/European Respiratory Society international multidisciplinary consensus classification of the idiopathic interstitial pneumonias. Am J Respir Crit Care Med. 2002; 165(2):277-304. PubMed doi:10.1164/ajrccm.165.2.ats01

47. Vanhees L, Lefevre J, Philippaerts R, et al. How to assess physical activity? How to assess physical fitness? Eur J Cardiovasc Prev Rehabil. 2005; 12(2):102-114. PubMed doi:10.1097/00149831-200504000-00004

48. Westerterp KR. Physical activity assessment with accelerometers. Int J Obes Relat Metab Disord. 1999; 23(3, Suppl.):S45-S49. PubMed doi:10.1038/sj.ijo.0800883

49. Wu CH, Kuo HC, Chang CS, Yu L. What extent of weight loss can benefit the health-related quality of life in motivated obese Chinese? Asia Pac J Clin Nutr. 2009; 18(3):423-432. PubMed

50. Yu CCW, Sung RYT, Hau KT, Lam PKW, Nelson EAS, So RCH. The effect of diet and strength training on obese children's physical self-concept. J Sports Med Phys Fit. 2008; 48(1):76-82. PubMed

51. Zabinski MF, Saelens BE, Stein RI, et al. Overweight children's barriers to and support for physical activity. Obes Res. 2003; 11:238-246. PubMed doi:10.1038/oby.2003.37 
Copyright of Pediatric Exercise Science is the property of Human Kinetics Publishers, Inc. and its content may not be copied or emailed to multiple sites or posted to a listserv without the copyright holder's express written permission. However, users may print, download, or email articles for individual use. 